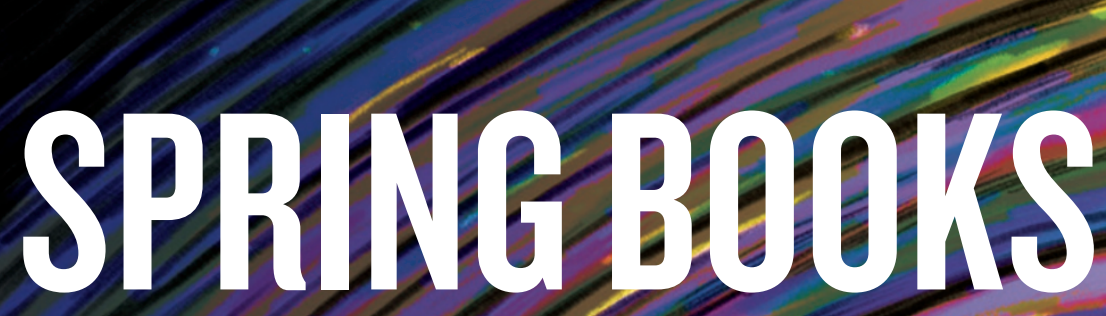

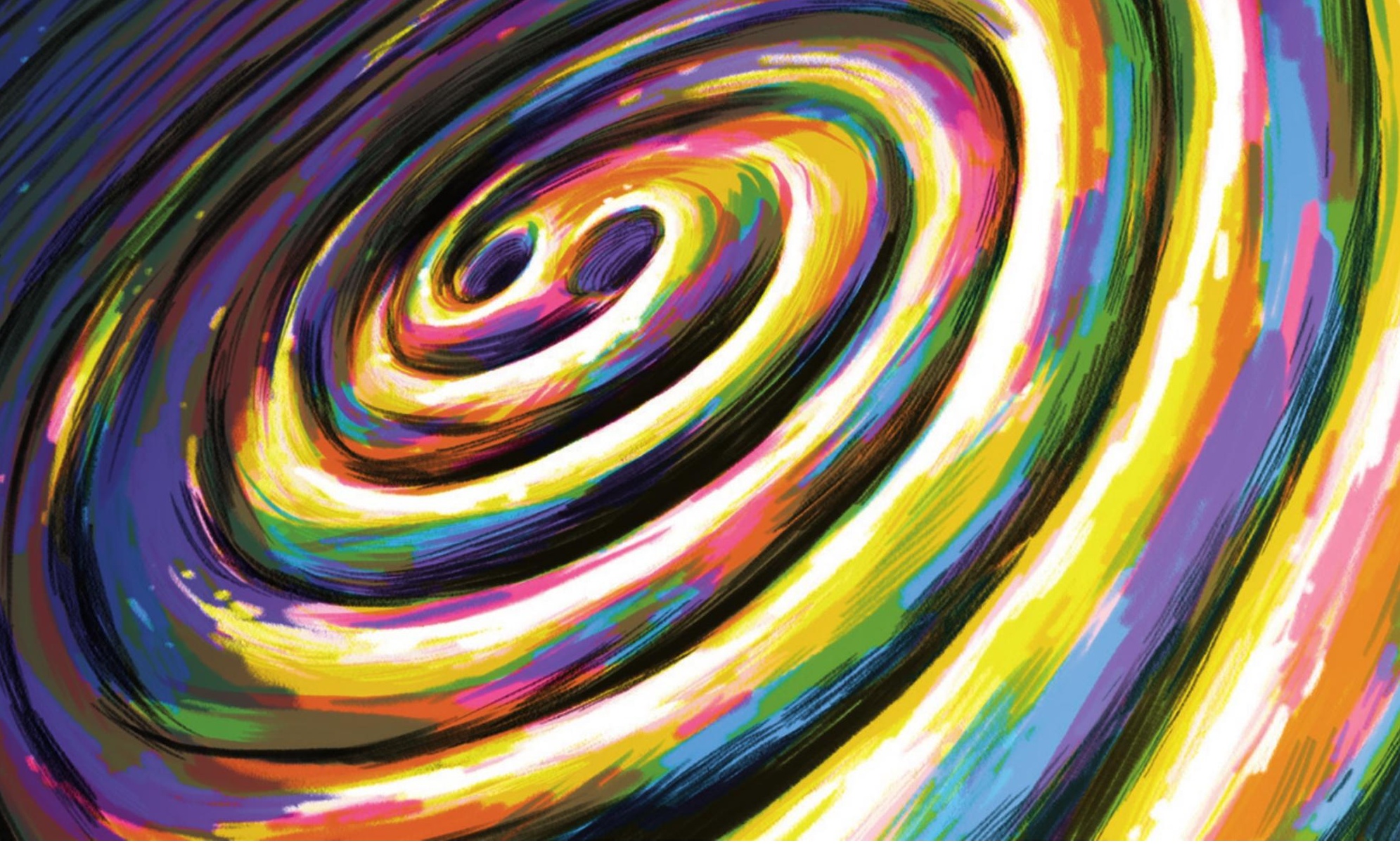

\section{Soundtrack of the Universe}

\section{Sheila Rowan ponders a chronicle of the long road to gravitational-wave detection.}

$\mathrm{G}$ ravitational waves were first detected on 14 September 2015 - a landmark event predicted a century before by Albert Einstein as part of his general theory of relativity. Janna Levin opens her chronicle of the long and twisting journey to the moment of detection, Black Hole Blues and Other Songs from Outer Space, with a quote from Niccolò Machiavelli's The Prince:

"There is nothing more difficult to take in hand, more perilous to conduct, or more uncertain in its success, than to take the lead in the introduction of a new order of things." Thus, words from a political treatise written in 1513 encapsulate the difficult birth of a new field: gravitational-wave astronomy.

The songs that Levin describes are the 'chirp' of almost unfathomably faint gravitational-wave signals: the soundtrack to

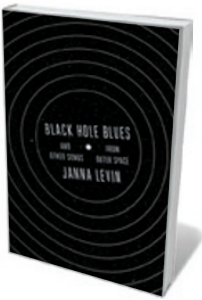

Black Hole Blues and Other Songs from Outer Space

JANNA LEVIN 2016.

\section{through interviews}

with key protagonists, including physicists Rainer Weiss, Ronald Drever, Kip Thorne and Rochus Vogt. She explains in clear terms the scientific heart of this achievement and the deep and personal fascination that pursuing it has held for several generations of scientists. She also captures the cost of getting to this point, both financial - this is big science in its truest sense - and, in many cases, personal. In different ways, we are led to see how, from an idea, a calculation, a basic experiment in a laboratory, the scientists involved drove the field forward from the 1960s, individually and then together.

This is not the first book on LIGO's history. Sociologist of science Harry Collins, for instance, has written several, including Gravity's Ghost and Big Dog (University of Chicago Press, 2013; see M. de Laet Nature 501, 164-165; 2013). Nor is it likely to be the last: the plot is too compelling. Verifying Einstein's prediction demanded precision technology and engineering beyond 
in unforeseen ways. Weiss and Drever, both strong leaders with individual ideas on process, and both passionate about the science, could not agree on a shared vision - even with Thorne's mediation. Decision-making became impossible, threatening to derail the project. Vogt was appointed to restore some measure of stability.

Scientists bring their whole history to their work: who they are shapes what they do, how they behave as leaders and how they make the research happen. So it is salutary to read about Drever's background and its part in his ingenuity and thrift. He produced a stream of remarkable scientific ideas, sometimes starting with limited means and materials. Levin describes Drever in Glasgow, UK, carrying out research on Lorentz invariance - testing fundamental aspects of the theory of relativity using basic materials in his back garden. But such inherent creativity does not necessarily sit easily with project management or the shared responsibilities that are part of leading a large scientific team.

Similarly, Levin describes how Vogt's management style was shaped by a dislike of authority that stemmed from experiences in his native Germany in the 1940s. This, too, became problematic in the stewardship of LIGO, which, among other qualities, demanded the ability to take the strain of significant external oversight and formality. Further changes in directorship followed, bringing the LIGO project to the stable, successful state in which it remains today. Levin touches on those only lightly.

Despite the upheavals, 'unreasonableness' - that singular drive on which "all progress depends", according to playwright George Bernard Shaw - was clearly essential to the forging of this new scientific field. Weiss, Drever and Vogt all had that crucial, extraordinary ability to persevere against prevailing forces to enable progress.

In many passages in Black Hole Blues, it is clear that we are reading the result of splitting the white light of truth through the prism of memory. In focusing mostly on the captivating details of a few individuals, the full picture is lost, the whole remains largely unsynthesized, and gaps at the joins sometimes show. Most noticeably, the details in Levin's chronicle stop around 20 years ago. We skip from the end of Vogt's tenure as LIGO director in the mid-1990s to the point at which the advanced LIGO instruments are about to take data in 2015. As interesting as Levin's narrative is, it leaves an entire exciting book still to be written.

of the difficult road ahead, although not the specific obstacles that would litter it.

For instance, as Levin shows, within a few years the project's leadership changed
Sheila Rowan is director of the Institute for Gravitational Research at the University of Glasgow, UK.

e-mail:sheila.rowan@glasgow.ac.uk at the detection of gravitational wave would be possible only through a combined 